\title{
The Economic Benefits Associated with Florida's Artificial Reefs ${ }^{1}$
}

\author{
Andrew Ropicki, Chuck Adams, Bill Lindberg, and John Stevely²
}

\section{Abstract}

Florida has the most permitted artificial reefs in the nation. This publication presents the results of several studies to determine the economic benefits of artificial reefs. It is intended as a helpful reference for resource managers, coastal community and state government agencies, reef user groups including fishers and divers, and Extension agents. The authors present findings by region, with sections on Pinellas County, Miami-Dade County, northwest Florida, southeast Florida, southwest Florida, Martin County, and the sinking of the USS Spiegel Grove (off of Key Largo), USS Oriskany (off of Pensacola), and the USS Vandenberg (off of Key West).

\section{Introduction}

Florida has one of the most active artificial reef programs among Gulf and Atlantic coast states. Approximately 3,750 artificial reef deployments are located off 34 coastal counties in Florida (Table 1). Although permitted by the United States Army Corps of Engineers and the Florida Department of Environmental Protection, artificial reefs are deployed under a set of guidelines established by the Florida Fish and Wildlife Conservation Commission. These guidelines are specified within the State of Florida Artificial Reef Strategic Plan (FFWCC 2003). Artificial reefs are utilized by recreational anglers, divers, and other user groups. The existence and use of artificial reefs set in motion a variety of economic activities that result in significant economic benefit to the coastal communities near the reefs. This publication will provide an overview of these economic benefits and briefly discuss some studies that have attempted to measure them and highlight the need for continued research.

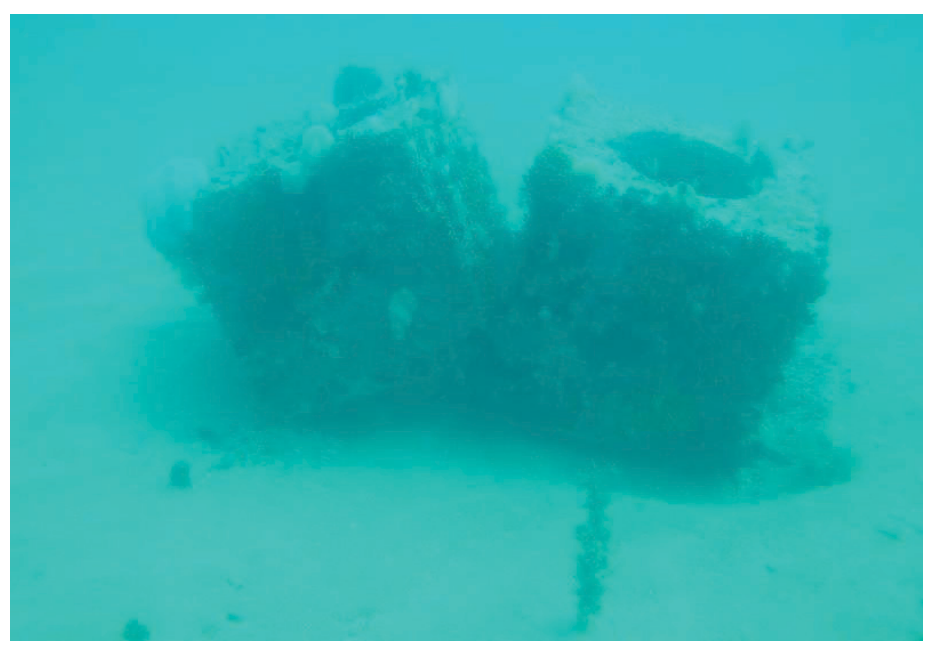

Figure 1. Artificial Reef in Taylor County, Florida.

Credits: Florida Sea Grant

\section{Benefits of Artificial Reefs}

Artificial reefs may be constructed for a variety of purposes, each with a set of potential benefits associated with that intended purpose or goal. One purpose of artificial reefs might be to provide a source of biological replenishment to

1. This document is FE649, one of a series of the Food and Resource Economics Department, UF/IFAS Extension. Original publication date August 2006. Revised March 2021. Visit the EDIS website at https://edis.ifas.ufl.edu for the most recent version of this publication.

2. Original written by Chuck Adams, emeritus professor, Food and Resource Economics Department; Bill Lindberg, emeritus associate professor, Fisheries and Aquatic Sciences Department; and John Stevely, UF/IFAS Florida Sea Grant marine Extension agent emeritus, UF/IFAS Florida Sea Grant College Program; revised by Andrew Ropicki, assistant professor, Food and Resource Economics Department, UF/IFAS Extension, Gainesville, FL 32611.

The Institute of Food and Agricultural Sciences (IFAS) is an Equal Opportunity Institution authorized to provide research, educational information and other services

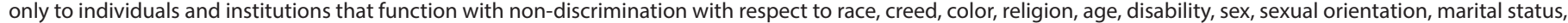

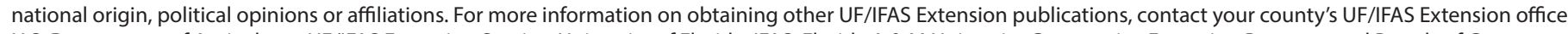
U.S. Department of Agriculture, UF/IFAS Extension Service, University of Florida, IFAS, Florida A \& M University Cooperative Extension Program, and Boards of County Commissioners Cooperating. Nick T. Place, dean for UF/IFAS Extension. 
local populations of marine vertebrates and invertebrates. In that case, the benefit would be that a net biomass increase would result from deploying the reef. Artificial reefs may also be used as a means of mitigating local habitat loss. Another purpose might be to simply provide a location where anglers and divers can utilize aggregated populations of marine species, either in a take (fishing) or no-take (viewing) fashion. The benefits in that case would be the increased economic activity (i.e., expenditures, incomes, jobs) associated with these practices. Each of these purposes may also generate non-market benefits (such as existence values), particularly to non-users of reefs. Such benefits reflect how individuals who may not directly use artificial reefs nonetheless value reef existence as being beneficial to the biological habitat of the region.

Aside from the purely biological benefits that might accrue from artificial reefs, many would argue that reefs are deployed to provide benefits to human users, whether commercial fishers, recreational anglers, sport divers, or others. Milon, Holland, and Whitmarsh (2000) suggest that "a reef that is not useful to people is not a successful reef." If this is an acceptable tenet, assessments of the economic benefits accruing from artificial reefs to surrounding communities are necessary. Such information provides insight into the degree to which the public benefit is being served by reef deployment and the economic consequences associated with reef use. The actual or potential economic impact of reef development to the county or state can be measured, and the extent to which artificial reef deployment is an efficient public investment can be determined. In turn, this information may help justify future public expenditures on artificial reefs and assist in developing adaptive strategies associated with reef deployment as a resource-management tool. Of course, there are costs associated with artificial reef program implementation. These costs must be measured as well.

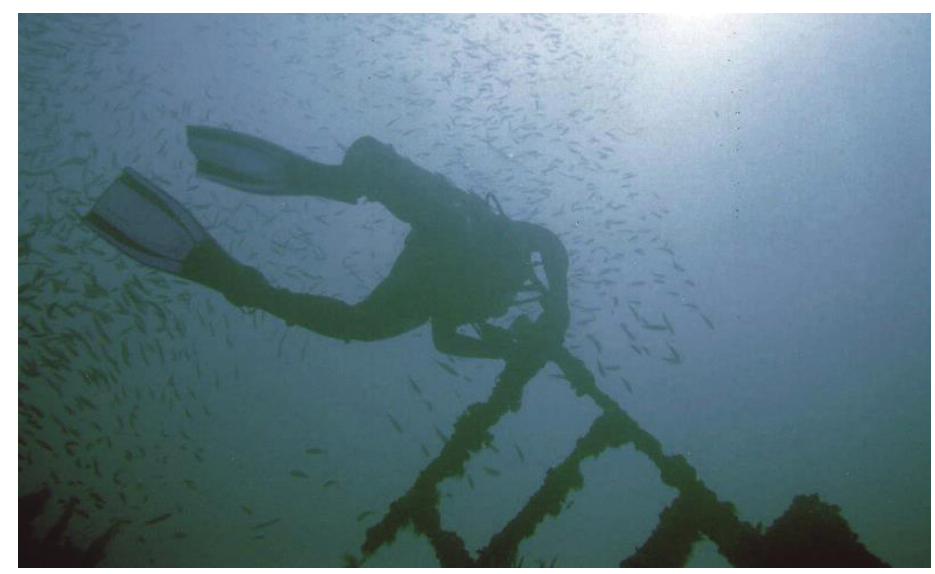

Figure 2. Diver on a Florida artificial reef. Credits: Rob Bronson, Jacksonville Reef Research Team. Used with permission

\section{Measuring the Economic Costs and Benefits}

The economic costs, activities, and benefits derived from artificial reef programs can be measured several ways. These are briefly reviewed below.

\section{Economic Impact Analysis}

This method can provide insight into how market-related activities associated with resident and non-resident expenditures change after reef deployment. An economic impact analysis will describe changes in economic activity within a given geographic region, such as expenditures, incomes, jobs, and business taxes.

\section{Contingent Valuation}

Contingent valuation is a survey-based method of valuing non-market environmental goods and services (Carson 2000). Individuals are asked their willingness to pay to obtain, or willingness to accept to give up, a good or service. While economic impact analysis can be employed in instances where expenditure data both pre- and post-reef deployment is available, the contingent valuation method can be employed prior to reef deployment to measure potential benefits associated with planned artificial reefs. Resource users, such as fishers and divers, can be asked how much they would be willing to pay for the construction of a new artificial reef.

\section{Cost Effectiveness Analysis}

This method can determine to what extent the estimated cost of deployment was realized in the actual reef deployment process. With limited local and state funds for reef development, ensuring that cost efficiency is maintained is vital to a sustainable county reef program. A cost effectiveness analysis will help ensure that reef programs are completed with a minimum of cost.

\section{Benefit/Cost Analysis}

This method takes into consideration the costs associated with the artificial reef site selection, permitting, deployment, monitoring, and other activities, and compares those costs to the suite of benefits that would be generated by the reef program. The benefits would include the total economic values associated with the overall public demand for the reef program. In this case, those benefit/ cost analysis estimates would include values reflected in the market, as well as those values associated with user and non-user demand for reefs over and above that reflected by reef-related expenditures in local markets. These benefits 
are often referred to as consumer surplus. Foregone benefits of utilizing reef-related funds in the next best use within the region may be included as an opportunity cost. A benefitto-cost ratio of greater than 1.0 suggests that the benefits associated with the program exceed the costs. This would be more desirable than a ratio less than 1.0, which would suggest that the costs derived from the reef program exceed the benefits. In the former case, the program would yield positive overall (net) economic benefits.

The methods listed above are the primary means of determining the net economic benefits associated with artificial reefs. Several such studies have been completed regarding Florida's artificial reefs. These studies have addressed artificial-reef-related changes in boater and angler use patterns and expenditures. They have examined the community/social impacts of artificial reef placement and the cost efficiency of reef projects, including the opportunity costs of utilizing scarce public funds for reef development. Some studies have attempted to address the overall economic values associated with artificial reefs, such as existence values and consumer surplus. Other studies have attempted to utilize the information to determine if the costs associated with artificial reef programs are exceeded by the benefits. Not all studies address each of these issues. Most of the studies are dated, and the results reflect the characteristics of the local economy and community structure at the time of the study. The key findings from these studies are briefly summarized below.

\section{Florida Artificial Reef Study Summaries}

\section{Pinellas County}

In one of the first such studies in Florida, Hanni and Mathews (1977) examined the costs associated with building an artificial reef system near Clearwater Beach. The intent of the study was to measure the potential economic benefits to anglers and divers who might utilize the reef. The study focused on the benefit-to-cost ratio of the reef program. The benefit-to-cost ratio for anglers was found to be greater than 1.0, while the benefit to cost ratio for divers was found to be less than 1.0.

In an attempt to examine the overall economic consequences of the artificial reef program in Pinellas County (which currently has the second highest number of permitted artificial reefs in Florida behind Bay County), Schug (1978) surveyed the users of the Pinellas County artificial reef system. The study found that the artificial reefs were not being utilized at the maximum use capacity. In fact, only 11 to 36 percent of the reef capacity was being utilized. In addition, 80 percent of the users were local. Thus, while most users were contributing little economic impact to the region, they were enhancing the total economic activity due to their reef-related activities. Total annual expenditures by reef users were estimated to be $\$ 181,000$ to $\$ 253,000$. The benefit-to-cost ratio of the artificial reef program in Pinellas County was estimated to be greater than 1.0.

\section{Miami-Dade County}

Miami-Dade County currently has the fifth largest complement of artificial reef deployments in Florida (Table 1).

Milon (1988) attempted to measure the economic benefits associated with the artificial reef program by users and non-users. The technique utilized was a mail-out survey to local boaters and divers. Respondents were asked to provide their willingness to pay for an artificial reef program. Of the respondents, 29 percent were anglers who frequented artificial reefs and 13 percent were divers who frequented artificial reefs.

Both users and non-users expressed positive benefits associated with the artificial reefs of Miami-Dade County. The annual benefits associated with artificial reefs in Miami-Dade County were estimated to be as high as $\$ 707,000$. Interestingly, the largest component of that amount was associated with non-users. Thus, artificial reefs have high values associated with those individuals who simply value the existence of such reefs but may never directly utilize them. The value associated with artificial reefs in Miami-Dade County ranged from $\$ 18$ million to $\$ 128$ million, based on estimation method.

\section{Northwest Florida}

The economic benefits associated with artificial reefs in northwest Florida were measured by Bell, Bonn, and Leeworthy (1998). The purpose of the study was to assess the economic impact, user valuation, and benefit-to-cost ratio associated with artificial reefs located in the waters adjacent to Escambia, Santa Rosa, Okaloosa, Walton, and Bay Counties.

A total of $\$ 414$ million in expenditures were associated with artificial reef use. Those expenditures supported 8,136 jobs and $\$ 84$ million in wages and salaries. Of the total expenditures, \$359 million and \$56 million were attributed to visitors and residents, respectively. Of the five counties studied, the total expenditures were distributed as follows: Bay (36\%), Okaloosa (30\%), Escambia (22\%), Santa Rosa (7\%), and Walton (5\%). The willingness to pay for an artificial reef program was also measured for the region. 
The annual recreational use value was estimated to be $\$ 19.7$ million, with a discounted asset value of $\$ 656$ million for the reef program. The benefit-to-cost ratio of the artificial reefs within the northwest Florida region was estimated to be 131, a value indicating an extremely high, positive return to the cost of developing and implementing the artificial reef programs within the five-county, northwest Florida region.

\section{Southeast Florida}

The economic impact and use values associated with artificial and natural reef systems in southeast Florida were analyzed by Johns, Leeworthy, Bell, and Bonn (2001). The methodology utilized was similar to that used in the study of the artificial reefs of northwest Florida. In addition, values associated with both the existing and potential new reef sites were assessed. The counties included in the study were Palm Beach, Broward, Miami-Dade, and Monroe.

The study found that non-residents and visitors annually spent $\$ 1.7$ billion on fishing and diving activities associated with artificial reefs. Of the total expenditures, Broward County contributed 53 percent, Miami-Dade County contributed 25 percent, and Palm Beach and Monroe Counties each contributed 11 percent. These expenditures generated approximately 27,000 jobs in the region and created $\$ 782$ million in wages and salaries. Interestingly, the expenditures associated with natural reef systems, in contrast to artificial reefs, generated $\$ 2.7$ billion in annual expenditures.

The annual recreational use value associated with existing artificial reefs in the region was estimated to be $\$ 84.6$ million. This annual value discounted into the future produced a discounted value of $\$ 2.8$ billion. The annual use value associated with any new artificial reefs was estimated to be $\$ 27$ million, with a discounted value of $\$ 888$ million. The annual willingness to pay for new artificial reefs was $\$ 4$ million. Interestingly, the annual recreational value associated with natural reefs was $\$ 228$ million, considerably more than that for artificial reefs.

\section{Martin County}

A study similar in methodology to the Palm Beach-Monroe Counties region study was conducted for Martin County, Florida. The study examined the values associated with artificial and natural reef systems. Johns (2004) examined annual expenditures, jobs, and incomes, as well as annual use values. The annual expenditures associated with artificial reef use were $\$ 7.2$ million. The contributions associated with resident and non-resident expenditures were approximately equal. The incomes associated with artificial reefs were estimated to be $\$ 3.2$ million, with approximately 100 jobs created within Martin County. The values associated with natural reefs were slightly smaller in magnitude.

The annual use value associated with existing artificial reefs (by residents and non-residents) was estimated to be $\$ 3.6$ million. This value discounted into the future was estimated to be $\$ 120$ million. The annual value associated with any new artificial reefs was estimated to be $\$ 1.1$ million, which when discounted into the future yielded a value of $\$ 37.5$ million.

\section{USS Spiegel Grove}

The USS Spiegel Grove was a retired navy ship that was sunk off Key Largo, Florida, in 2002. The primary purpose of the Spiegel Grove deployment as an artificial reef was to determine whether introducing an artificial reef in close proximity to a natural reef environment would reduce usage of the surrounding natural reefs. Thus, the primary objective was from a resource-management perspective. However, economic implications were in question as well. A key question was whether the local economy would benefit from deploying artificial reefs whose primary purpose would be redirecting diver use away from natural reefs. A study was conducted on use patterns and local economic activity before and after the Spiegel Grove deployment (Leeworthy, Maher, and Stone 2005; Leeworthy, Maher, and Stone 2006). The study provided insight into how the Spiegel Grove performed as a substitute by divers and snorkelers for local natural reefs, as well as what benefits to the local economy occurred.

Regarding the resource-management objective, the Spiegel Grove artificial reef was deemed a success. Following the deployment, the diver and snorkeler use of natural reefs within the study area declined by 13.7 percent. In addition, the number of dive charters specifically for natural reefs within the region declined by 16.7 percent. However, the total number of dive charters and other related dive/ snorkel activity increased substantially. The net change in expenditures on diving and snorkeling activities increased $\$ 2.6$ million during the study period, with approximately 80 percent of that increase being attributed to non-residents. Incomes within the local economy increased by $\$ 960,000$, and an additional 68 jobs were created. Thus, the deployment of the Spiegel Grove was considered a win-win situation for both the natural reef environment and the local economy. 


\section{USS Oriskany}

The decommissioned Essex Class attack aircraft carrier, the USS Oriskany, was sunk off the coast of Pensacola, Florida, on May 17, 2006. The original 2004 deployment was delayed due to further PCB (polychlorinated biphenyl) abatement needs and hurricanes. The successful completion of the project, which involved obtaining, preparing, transporting, and sinking the vessel, was due to the combined efforts of several county, state, and federal agencies. At the time of the sinking, the Oriskany was the largest artificial reef structure ever deployed. The Oriskany was sunk at a depth and distance from shore that would preclude most novice divers, with the top of the "island" being at 60 feet and the flight deck at 130 feet. Diving to the flight deck and hangar deck (150 feet) is better suited to those with technical diving skills (i.e., nitrox and trimix).

The primary purpose of the deployment was to enhance the coastal economic activity associated with the recreational dive industry located in the Baldwin County (Alabama) and Escambia County (Florida) regions. Analyses on both single- and two-county scenarios indicated significant economic activities and impacts were realized during the year immediately following the deployment of the Oriskany (Haas Center 2007). Approximately 4,200 chartered dive trips were taken to the Oriskany during the first year after the sinking. Average expenditures for dive trips originating from non-local destinations were estimated to be $\$ 463$, while an average local dive trip resulted in expenditures of \$352. Dive activities originating from Baldwin and Escambia Counties combined resulted in dive-trip-related expenditures of $\$ 2.2$ million, with an economic impact of $\$ 3.6$ million, the creation of 67 jobs, and the generation of $\$ 1.4$ million in local incomes. Dive activities originating from Escambia County only resulted in dive-trip-related expenditures of $\$ 1.2$ million, with an economic impact of $\$ 2$ million, the creation of 37 jobs, and the generation of $\$ 740,000$ in local incomes.

The Oriskany also provided the opportunity to examine the preferences of divers for existing and hypothetical dive opportunities. For example, the perceived value of the possibility of "bundling" (locating a smaller sunken vessel in the proximity of the Oriskany but closer to shore) and thereby increasing the use opportunities of a hypothetical complement of artificial reefs, was examined (Morgan, Massey, and Huth 2009). Subsequent analyses have shown that the concept of bundling additional reef sites does increase the perceived use values associated with large ship artificial reef deployments.

\section{USS Vandenberg}

The 520-foot USS Vandenberg was a retired United States Air Force missile tracking ship that was sunk off Key West, Florida, in May 2006. The vessel was placed within the Florida Keys National Marine Sanctuary. The primary purpose of the deployment was to enhance local economic development and tourism. The total cost of preparing and sinking the vessel amounted to $\$ 8.6$ million. Subsequent studies have shown that the Vandenberg has increased activities within the local dive charter industry, as well as the local economy in general (Office of National Marine Sanctuaries 2011). Following the sinking of the Vandenberg, the local dive-related business increased by almost 190 percent. This resulted in an increase of $\$ 6.5$ million in expenditures, while annual state and local sales and lodging tax revenues increased by approximately $\$ 620,000$. An additional 105 jobs, with $\$ 3.2$ million in incomes, were generated by the deployment of the Vandenberg as an artificial reef.

Similar to the USS Spiegel Grove project, an additional objective of the Vandenberg artificial reef project was to assess the diversion of divers and snorkelers from natural reefs to the nearby artificial reef-the Vandenberg. As hypothesized, the total use of natural reefs by divers and snorkelers did decline, but the overall increase in activity due to the presence of the Vandenberg resulted in a net increase in the use of nearby natural reefs.

\section{Southwest Florida}

A study by the University of Florida focused on the economic impact that artificial reef deployments have had on six counties in southwest Florida: Pinellas, Hillsborough, Manatee, Sarasota, Charlotte, and Lee (Swett, Adams, Larkin, Hodges, and Stevens 2011). The study found that approximately 614,000 boating days and over 2 million person days were spent annually utilizing the artificial reefs within the six-county region, with 5,600 persons using the reefs each day. The primary users of the artificial reefs were private boaters; however, the for-hire sector (guide, party, and charter clients) was also found to be an important user of the complement of artificial reefs in the region. In fact, this study was the first to provide clear insight into the role that the for-hire sector plays in the utilization of Florida's artificial reefs.

The use of artificial reefs in the six-county region resulted in annual expenditures of \$253 million, of which \$136 million was spent by residents in the region and $\$ 117$ million was spent by non-residents. Of the total expenditures, $\$ 163$ million was spent by private boaters, while $\$ 90$ million was 
spent by clients of the for-hire sector. The annual expenditures on artificial reefs generated economic impacts of \$227 million, along with \$122 million in incomes and \$17 million in business taxes. It created approximately 2,600 jobs. In addition, the study found strong public support for the use of public funds toward providing and maintaining artificial reefs in Florida waters.

\section{Need for Additional Research}

While the late 1990s and early 2000s were marked by a great deal of research on the economic importance of Florida's artificial reefs, a lack of recent research has led to a gap in our understanding of how these reefs benefit the economies of Florida's coastal communities and the state as a whole. While previous studies provide insights on economic contributions of these reefs, these studies are geographically and temporally specific to the artificial reef and time period being studied. Changes in artificial reef usage and spending patterns could lead to inaccurate assumptions regarding the current benefits provided by existing and new artificial reefs. Additionally, the number of artificial reefs in Florida increased 65\% between 2011 and 2020 with multiple counties doubling the number of reefs in their waters (FFWC 2021). Because of this, additional research is needed to determine if the marginal benefits of new reef construction have changed significantly. Have new reefs simply cannibalized trips that would have been taken to existing reefs, or is the increase in the number of artificial reefs in Florida justified by increased demand and usage? New research on the economic contributions of Florida's artificial reefs would allow for a timely analysis of the costs and benefits associated with recent and future artificial reef construction projects.

\section{Summary}

Florida reportedly has the largest complement of permitted artificial reefs in the nation. These reefs have been shown to be beneficial to the local economies. The studies reviewed above show that artificial reefs do increase economic activity in surrounding communities. Because artificial reefs are valued by users and non-users alike and generally provide benefits that exceed costs, they may be an effective tool for redirecting use away from natural reefs if such a management objective is required. Overall, artificial reefs are a source of economic value that may justify additional deployments, even after taking into account the opportunity costs associated with scarce public funds. However, a paucity of recent studies combined with growth in the number of reefs has left questions on the economic benefits of recent and planned future reef construction, which require additional research.

\section{References}

Bell, F. W., M. A. Bonn, and V. R. Leeworthy. 1998. Economic Impact and Importance of Artificial Reefs in Northwest Florida. Office of Fisheries Management and Assistance Service, Florida Department of Environmental Administration, Tallahassee, FL.

Carson, R. T. 2000. “Contingent Valuation: A User's Guide.” Environmental Science \& Technology 34 (8): 1413-1418.

Florida Fish and Wildlife Conservation Commission [February 2021]. Artificial Reef Deployment Data. Division of Marine Fisheries Management, Tallahassee, FL. Data found on the following website: http://myfwc.com/conservation/ saltwater/artificial-reefs/

Florida Fish and Wildlife Conservation Commission. 2003. State of Florida Artificial Reef Strategic Plan. Division of Marine Fisheries Management, Tallahassee, FL.

Haas Center. 2007. The Economic Impact of Diving the USS Oriskany on the Regional Economy. The Haas Center for Business Research and Economic Development, The University of West Florida, Pensacola, FL.

Hanni, E., and H. H. Mathews. 1977. Benefit-Cost Study of Pinellas County Artificial Reefs. FLSGP-T-77-005. Florida Sea Grant College Program, UF/IFAS Extension, Gainesville, FL.

Johns, G. 2004. Socioeconomic Study of Reefs in Martin County, Florida. Report prepared for Martin County, Florida by Hazen and Sawyer, P.C., Hollywood, FL.

Johns, G., V. R. Leeworthy, F. W. Bell, and M. A. Bonn. 2001. Socioeconomic Study of Reefs in Southeast Florida. Report prepared for Miami-Dade County, Florida by Hazen and Sawyer, P.C., Miami, FL.

Leeworthy, V. R., T. Maher, and E. A. Stone. 2005. Can artificial reefs reduce or alter user pressure on adjacent natural reefs? Coastal and Ocean Resource Economics Program, Special Projects Office, National Ocean Service, National Oceanic and Atmospheric Administration, Silver Spring, MD. 
Leeworthy, V. R., T. Maher, and E. A. Stone. 2006. “Can artificial reefs reduce or alter user pressure on adjacent natural reefs?" Bulletin of Marine Science 78 (1): 29-37.

Milon, J. W. 1988. The Economic Benefits of Artificial Reefs: An Analysis of the Dade County, Florida Reef System. SGR90. Florida Sea Grant College Program, UF/IFAS Extension, Gainesville, FL.

Milon, J. W., S. Holland, and D. Whitmarsh. 2000. Social and Economic Evaluation Methods. Evaluating Artificial Reefs and Related Aquatic Habitats, edited by W. Seaman. Boca Raton, FL: CRC Press.

Morgan, O. A., D. M. Massey, and W. L. Huth. 2009. Diving Demand for Large Ship Artificial Reefs. Marine Resource Economics 24 (1): 43-59.

Office of National Marine Sanctuaries. 2011. Socioeconomic Monitoring Program for the Florida Keys National Marine Sanctuary-Recreation/Tourism: New Artificial Reefs. National Oceanic and Atmospheric Administration (NOAA), Silver Springs, MD. http://sanctuaries.noaa.gov/ science/socioeconomics/floridakeys/recreation/new_reefs. html.

Schug, D. M. 1978. Political and Economic Aspects of Artificial Reefs in Pinellas County, Florida. M.S. Thesis, Department of Marine Science, University of South Florida, Tampa, FL.

Swett, R. A., C. Adams, S. Larkin, A. W. Hodges, and T. J. Stevens. 2011. Economic Impacts of Artificial Reefs for Six Southwest Florida Counties. TP-178. Florida Sea Grant College Program, UF/IFAS Extension, Gainesville, FL. 
Table 1. Number of artificial reef deployments in Florida by county.

\begin{tabular}{|c|c|}
\hline County & \# of Reefs \\
\hline Bay & 478 \\
\hline Brevard & 68 \\
\hline Broward & 123 \\
\hline Charlotte & 34 \\
\hline Citrus & 25 \\
\hline Collier & 121 \\
\hline Dade & 246 \\
\hline Dixie & 27 \\
\hline Duval & 103 \\
\hline Escambia & 329 \\
\hline Flagler & 14 \\
\hline Franklin & 68 \\
\hline Gulf & 21 \\
\hline Hernando & 26 \\
\hline Hillsborough & 75 \\
\hline Indian River & 17 \\
\hline Lee & 124 \\
\hline Levy & 31 \\
\hline Manatee & 98 \\
\hline Martin & 117 \\
\hline Monroe & 62 \\
\hline Nassau & 18 \\
\hline Okaloosa & 285 \\
\hline Palm Beach & 125 \\
\hline Pasco & 37 \\
\hline Pinellas & 363 \\
\hline Santa Rosa & 46 \\
\hline Sarasota & 204 \\
\hline St. Johns & 40 \\
\hline St. Lucie & 77 \\
\hline Taylor & 50 \\
\hline Volusia & 177 \\
\hline Wakulla & 80 \\
\hline Walton & 47 \\
\hline TOTAL & 3,756 \\
\hline
\end{tabular}

